\title{
ESTADO MECÂNICO-CORROSIVO DE JUNTAS SOLDADAS PELO PROCESSO MIG-MAG DO AÇO INOXIDÁVEL SUPERDUPLEX SAF 2507*
}

Bruno Leonardy Sousa Lopes Eden Santos Silva ${ }^{2}$ Samuel Filgueiras ${ }^{3}$

Waldemir dos Passos Martins ${ }^{4}$ Valdemar Silva Leal ${ }^{5}$

\section{Resumo}

Este trabalho tem como objetivo mostrar a correlação entre as fases constituintes do aço superdúplex SAF 2507 na junta soldada por processo MIG-MAG, considerando os efeitos da energia de soldagem nas propriedades mecânicas e de corrosão. Os resultados mostraram que a energia de soldagem causou mudanças no balanço das fases $\alpha / y$, na formação pontual da fase $\sigma$ nos contornos de grãos ferriticos e mudanças de microdureza e tenacidade nas regiões da zona fundida (ZF) e zona termicamente afetada (ZTA), além de promover o aumento da fase y e do índice de resistência à corrosão por pite $\left(P R E N_{Y}\right)$, quanto maior energia de soldagem. Entretanto, a tenacidade na ZF diminuiu mesmo com maior formação da fase $\gamma$, coalescimento dos grãos ferriticos, elevando a microdureza na ZTA sob baixa energia de soldagem. Assim, espera-se que estes resultados permitam estabelecer diretrizes para procedimentos de reparo em aços superdúplex sob processo de soldagem

Palavras-chave:Aços superduplex; Soldagem; Tenacidade e corrosão por pite.

\section{STATE MECHANIC-CORROSION OF WELDED JOINTS BY THE MIG - MAG PROCESS OF STAINLESS STEEL SAF 2507 SUPERDUPLEX}

\section{Abstract}

This work aims to show the correlation between the constituent phases of SAF 2507 superduplex steel in the welded joint by MIG-MAG process, considering the effects of welding energy in the mechanical properties and corrosion resistance. The results showed that welding energy caused changes in the balance of $\alpha / \gamma$-phases, the spot formation of $\sigma$-phase in the ferritic grain boundaries and produced changes in hardness and toughness in the regions of the fusion zone (ZF) and heat affected zone (HAZ), in addition to promoting increased $\mathrm{Y}$-phase and resistance to pitting corrosion index (PRENy), the higher power welding. However, the toughness in ZF decreased with lower formation of $\mathrm{y}$-phase coalescence of ferritic grains and formation of $\sigma$-phase, increasing hardness in the HAZ under low energy welding. Thus, it is expected that these results allow establishing guidelines for repair procedures in superduplex steels in welding process.

Keywords: Superduplex steel; Welding; Toughness; Pitting corrosion.

1 Engenheiro Mecânico/ Engenheiro Mecânico, Especialista, Professor EBTT/Professor, Departamento de Mecânica e Materiais (DMM), Instituto Federal do Maranhão (IFMA), São Luis, Maranhão e Brasil.

2 Físico/Física, Doutor, Professor/, Engenharia Civil/Engenharia Civil, Unidade de Ensino Superior Dom Bosco, São Luis, Maranhão, Brasil.

3 Físico/Físico, Mestre, Professor EBTT/Professor, Departamento de Mecânica e Materiais (DMM), Instituto Federal do Maranhão (IFMA), São Luis, Maranhão e Brasil.

4 Engenheiro Mecânico/ Engenheiro Mecânico, Doutor, Professor/Professor, Departamento de Mecânica e Materiais (DMM), Instituto Federal do Maranhão (IFMA), São Luis, Maranhão e Brasil

5 Engenheiro Mecânico/ Engenheiro Mecânico, Doutor, Professor/ Professor, Departamento de Mecânica e Materiais (DMM), Instituto Federal do Maranhão (IFMA), São Luis, Maranhão/ Brasil. 


\section{INTRODUÇÃO}

O desenvolvimento de ligas inoxidáveis significa grandes avanços na fabricação de materiais de alta resistência mecânica, apropriada resistência à corrosão e boa soldabilidade. Os aços inoxidáveis são aços de alta liga com no máximo 1,2\% de Carbono, cujas bases são os sistemas Fe-Cr-C e Fe-Cr-Ni, com no mínimo 10,5\% de Cromo em solução de modo que quando exposto a atmosfera contendo Oxigênio formam camadas passivas de óxidos que impedem o contato do metal de base com atmosferas agressivas. De acordo com seu aspecto microestrutural são classificados nas famílias: Ferriticos, Martensiticos, Austeniticos, Endurecíveis por precipitação e Dúplex/Superdúplex [1].

Os aços inoxidáveis superdúplex (AISD) são ligas do tipo Fe-Cr-Ni-Mo-N usados numa grande variedade de aplicações, tais como, indústria química, petroquímica, planta industrial de óleo e gás, manufatura de produtos tubulares e indústria estrutural offshore [1]. Nessas indústrias é essencial o uso de materiais com excelentes propriedades mecânicas e de corrosão, especialmente em componentes que operam em ciclos sob carregamento severo em ambientes altamente agressivos, como $\mathrm{Cl}^{+}, \mathrm{NaCl}, \mathrm{H}_{2} \mathrm{~S}, \mathrm{CO}_{2}$ e CN, com extrema necessidade de condições de segurança operacional [2]. A utilização destas ligas também tem sido justificada devido às recentes explosões de reservas de petróleo e gás na camada do pré-sal, proporcionando a extração de petróleo com componentes mais corrosivos e em profundidades cada vez maiores, necessitando assim do emprego de materiais de alto desempenho contra o desgaste e a corrosão localizada [2].

Estudos na literatura têm sido reportados no intuito de compreender os mecanismos mecânicos e corrosivos que delineiam a formação preferencial das fases presentes nas ligas, como função da energia de soldagem, balanço microestrutural, fases intermetálicas nas regiões da zona fundida (ZF), zona termicamente afetada (ZTA) e metal de base (MB) [3]. Esses estudos incluem os mecanismos de resistência mecânica, assim como as respostas à susceptibilidade ao estado corrosivo por pite, anomalias que podem promover falhas nos equipamentos sem aviso prévio [3].

Os aços superdúplex constituem uma família de aços com frações aproximadamente iguais de fase microestrutural ferrita ( $\alpha$ ) e austenita ( $($ ), $50 / 50$ em volume [2,3]. Esta microestrutura pode ser obtida através do balanceamento dos elementos de liga, tratamento térmico e/ou termomecânico. Nestas ligas, essa fração de fase é um fator determinante no comportamento mecânico, físico, químico e de soldabilidade sob diversas atmosferas. A alteração desta fração pode induzir tensões internas no material com formação de trincas durante o resfriamento na soldagem com diferentes ciclos térmicos e modificação de propriedades mecânicas por conta da formação de compostos intermetálicos nos contornos de grãos das fases, tais como fase $\sigma$, carbonetos $\left(\mathrm{M}_{23} \mathrm{C}_{6}\right)$ e nitreto de cromo $\left(\mathrm{Cr}_{2} \mathrm{~N}\right)$, definido segundo as condições de tempo - temperatura. Além disso, pode haver mudança de composição química dos constituintes, tal como a ferrita a (CCC) e a austenita y (CFC), por conta da partição dos elementos de liga [3].

A fase ferrita ( $\alpha$ ) é estável e rica em Cromo e Molibdênio com alta taxa de difusão, excelentes propriedades mecânicas, alto limite de escoamento e maior dependência com a temperatura, devido ao tamanho de grão fino da microestrutura, oportuno aos processos de soldagem [3]. Entretanto, a fase austenita ( $\mathrm{Y}$ ) é estável e rica em Niquel, Manganês e Nitrogênio, com elevada tenacidade e ductilidade. Alguns desses elementos que são adicionados como elemento de liga na austenita pode participar e gerar processos corrosivos por pite $[1,2]$. Assim, a alteração na fração de 
fase $(\alpha / y)$ pode causar mudanças nas propriedades de tenacidade, ductilidade e resistência à corrosão por pite na liga.

Nos aços superdúplex a presença das fases ferritica e austenitica dificultam sua manutenção na proporção 50/50 pelo efeito dos ciclos térmicos de soldagem, aplicação localizada de calor, deformação plástica, variação da composição química nas reações durante a solidificação e resfriamento do cordão de solda pelo controle de temperatura que varia da ZF até o metal adjacente a ZTA, onde ocorrem transformações no estado sólido [3]. Sendo a principal finalidade do processo de solda manter excelente resistência à corrosão na ZF e na ZTA. Neste formalismo a energia necessária para fundir os metais de base e de adição é gerada pelo arco elétrico, dado pela Equação 1 (Energia de soldagem, $\mathrm{kJ} / \mathrm{mm}$ ):

$$
E=\eta \frac{U . i}{v_{s}}
$$

(Equação 1)

onde $\boldsymbol{\eta}$ é o rendimento térmico do processo, $\boldsymbol{i}$ é a corrente transferida, $\boldsymbol{U}$ a tensão aplicada e $\boldsymbol{V}_{\boldsymbol{s}}$ a velocidade de soldagem [4]. Este controle permite estabelecer diretrizes de reparo em estruturas ou defeitos de fabricação.

A resistência à corrosão por pite nos aços inoxidáveis em geral tem sido calculado a partir do PREN (Número equivalente de resistência à corrosão por pite), medida empírica reportada na literatura como função dos teores dos elementos de liga que compõem o material, tais como $\mathrm{Cr}, \mathrm{Mo}, \mathrm{Mn}$ e N, segundo a Equação 2 [5]:

$$
P R E N=[\% \mathrm{Cr}]+3,3[\% \mathrm{Mn}]+\xi[\% \mathrm{~N}]-[\% \mathrm{Mn}] \quad \text { (Equação 2) }
$$

onde o parâmetro $16<\zeta<30$. Por exemplo, o aço dúplex UNS $S 32550$ apresentou índice de pite de 38, maior que o valor de referência. A partir deste valor empírico é possível mensurar a resistência à corrosão por pite das fases e aperfeiçoar o balanceamento $\alpha / \gamma$ [6]. Os aços superdúplex se distinguem por possuir um PREN maior que 40. Mas existem algumas questões não esclarecidas, tais como: o inicio da corrosão por pite não se caracteriza somente nas condições de baixas concentrações das fases; a resistência à corrosão por pite diminui sempre com o acréscimo na fração de ferrita $\alpha$; o PREN da liga difere dos PREN das fases.

Este trabalho tem como objetivo esclarecer a correlação entre as fases constituintes do aço superdúplex SAF 2507 na junta soldada das regiões ZF-ZTA-MB por processo de soldagem a arco com proteção gasosa MIG-MAG, considerando os efeitos da energia de soldagem na dureza, tenacidade e na corrosão por pite.

\section{MATERIAIS E MÉTODOS}

O material investigado neste trabalho foi o aço superduplex SAF 2507 em forma de chapas com dimensões de $250 \times 250 \times 6 \mathrm{~mm}$, o metal de adição foi arame superduplex ER 2594. A composição química nominal é apresentada na Tabela 1. Segundo a literatura o aço SAF 2507 apresenta boas propriedades mecânicas, tais como limite de escoamento, $\sim 566 \mathrm{MPa}$, limite de resistência, $\sim 836 \mathrm{MPa}$, alongamento, $\sim 25 \%$ e alta dureza das fases presentes, $\sim 286 \mathrm{Hv}$ fase $\alpha$ e $\sim 272 \mathrm{Hv}$ fase $\mathrm{y}[6]$.

Para certificação da composição do material como recebido e identificação das fases presentes no aço superdúplex SAF 2507 a diferentes condições de energia de soldagem, o material foi analisado por difração de raios $X$, no difratômetro modelo $X$ 
Pert PRO e também o cálculo do diagrama de fase de equilíbrio via Facstage para estimar as fases presentes na liga.

Tabela 1 Composição química nominal do aço superdúplex SAF 2507 (\% massa).

\begin{tabular}{ccccccccccc}
\hline Material & $\mathbf{C r}$ & $\mathbf{M o}$ & $\mathbf{N i}$ & $\mathbf{C}$ & $\mathbf{N}$ & $\mathbf{M n}$ & $\mathbf{S i}$ & $\mathbf{P}$ & $\mathbf{S}$ & $\mathbf{F e}$ \\
\hline $\begin{array}{c}\text { Aço SAF } \\
\mathbf{2 5 0 7}\end{array}$ & 24,95 & 3,79 & 6,91 & 0,015 & 0,263 & 0,43 & 0,26 & 0,017 & 0,001 & bal. \\
$\begin{array}{c}\text { Metal } \\
\text { adição }\end{array}$ & 24,92 & 3,9 & 9,19 & 0,011 & 0,28 & 0,6 & 0,46 & 0,019 & 0,005 & bal. \\
\hline
\end{tabular}

A soldagem foi realizada seguindo o processo MIG-MAG com transferência curtocircuito convencional e pelo derivativo STT utilizando como metal de adição o arame superduplex ER 2594 e gás de proteção Argônio $\left(\mathrm{Ar}+2 \% \mathrm{O}_{2}\right)$ com configuração da junta a ser soldada em forma de V, conforme Figura 1. A soldagem ocorreu com auxilio de uma fonte PW- 455m/STT ligada a um braço robotizado HP-20 para deslocamento automático da tocha de soldagem e temperatura interpasse de $40{ }^{\circ} \mathrm{C}$ com três valores de energia de soldagem: $\mathrm{EJ}_{1}=0,607 \mathrm{~kJ} / \mathrm{mm}$ (raiz STT enchimento curto-circuito convencional), $E_{\mathrm{J} 2}=0,633 \mathrm{~kJ} / \mathrm{mm}$ (raiz STT enchimento curto-circuito convencional) e $E_{J 3}=0,427 \mathrm{~kJ} / \mathrm{mm}$ (raiz STT enchimento STT), com variação de corrente de 85 e 120A e voltagem entre 14,6 e 17,3V.

Após o procedimento de soldagem foram retiradas as amostras com cortes na direção longitudinal com dimensões de $6 \times 6 \times 60 \mathrm{~mm}$ para realização dos ensaios de microdureza no microdurômetro modelo Galileo D200, seguindo a norma Petrobras $\mathrm{N}-133 / 14$ [4], em escala Vickers $(\mathrm{Hv})$, mapeando as variações de microdureza nas regiões trifásicas ZF-ZTA-MB sob pontos equidistantes a cada 0,5 $\mathrm{mm}$, partindo do centro da ZF. Assim foram realizadas três colunas de medidas com dez pontos distintos, inicialmente no ZF e se estendendo até o MB.

Os ensaios de impacto por Charpy seguiu-se as especificações de norma ASTM E 23 [5], realizado numa máquina de ensaio de impacto Tinius Olsen LT 032, na condição de temperatura ambiente $25^{\circ} \mathrm{C}$ e a $-40^{\circ} \mathrm{C}$. Os ensaios de impacto foram realizados nas três regiões ZF-ZTA-MB com três corpos de prova para cada situação com dimensões de $5 \times 5 \times 55 \mathrm{~mm}$ : Junta 1 STT e convencional; Junta 2 STT e convencional e Junta 3 STT. Os ensaios de corrosão por pite foram realizados conforme a norma ASTM G 48, método A [4], que possibilita avaliar a perda de massa do aço por imersão em solução de cloreto ferrítico $\left(\mathrm{FeCl}_{3}\right)$ a temperatura de $22{ }^{\circ} \mathrm{C}$.

A caracterização microestrutural, foi realizada através de microscopia ótica (MO) Olympus, modelo BX51M, após tratamento metalografico padrão, seguindo a norma ASTM E7-03 [6], para revelação dos contornos de grãos das fases presentes, foi realizado ataque eletrolítico com solução de $10 \%$ de acido oxálico, e para diferenciação das fases foi usado uma solução de behara modificado para atacar a superfície do material, determinadas por microscópio eletrônico de varredura (MEV) acoplado ao dispositivo de microanalise por espectroscopia por dispersão de energia (EDS) que possibilitou identificação das fases. 


\section{RESULTADOS E DISCUSSÃO}

A Figura 1 mostra as microestruturas das três juntas com diferentes energias de soldagem. Nota-se a coexistência das três regiões características: zona fundida $(\mathrm{ZF})$, zona termicamente afetada (ZTA) e metal de base (MB). Vê-se que na região de ZF há formação de grãos epitaxiais estruturados em forma de agulhas tipo Widmanstatten que crescem nos grãos ferriticos formando grãos finos equiaxias. Há também a formação de grãos intergranulares na fase a e estruturas alotriomórficas nos contornos de grãos ferriticos. Já na ZTA há formação de uma microestrutura mista colunares adjacente a ZF com desenvolvimento dos grãos ferriticos, resultante do aquecimento acima da temperatura de recristalização e crescimento com migração dos contornos de grãos e presumível redução na resistência mecânica pelo calor envolvida no processo.
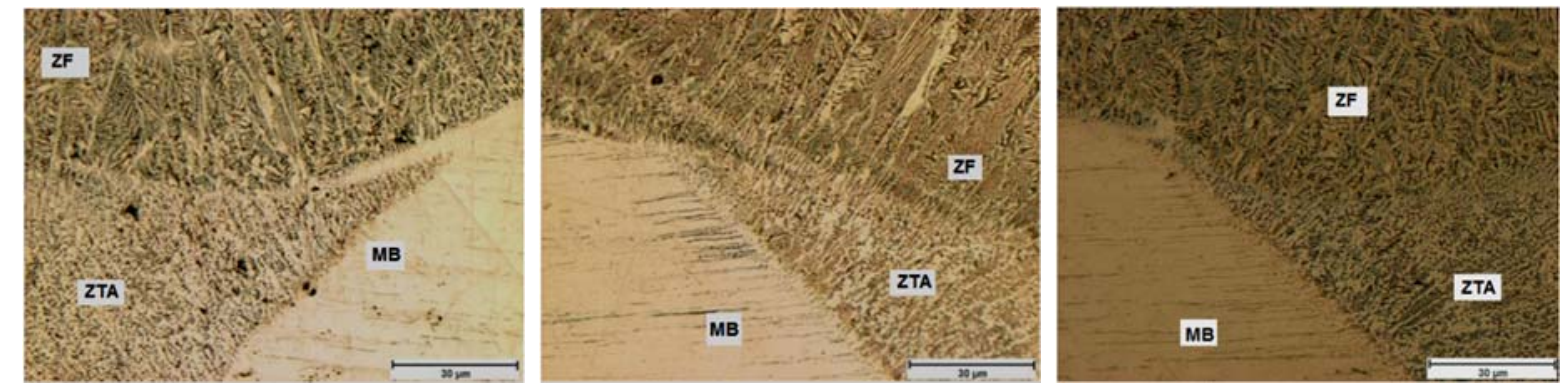

Figura 1 Microestruturas das juntas soldadas com as três fases ZF-ZTA-MB: a) J1 $\left.\left(E_{J 1}=0,607 \mathrm{~kJ} / \mathrm{mm}\right) ; b\right) \mathrm{J} 2\left(E_{J 2}=0,633 \mathrm{~kJ} / \mathrm{mm}\right)$ e c $) \mathrm{J} 3\left(E_{\mathrm{J} 1}=0,427 \mathrm{~kJ} / \mathrm{mm}\right)$.

A Figura 1 apresenta uma região trifásica transiente das juntas entre a ZF-ZTA-MB. Note que a formação de grãos é limitada e ocorre crescimento de grãos no ZF, com variação morfológica em diferentes pontos da junta na região ZF-ZTA, causando variações localizadas de microestrutura e prováveis mudanças de microdureza e tenacidade. Observe que existe diferença na forma dos grãos entre a interface ZFZTA, sendo a quantidade da fase austenita $(\mathrm{Y})$ nas três regiões maior que de ferrita $(\alpha)$, mas com os grãos de ferrita mais grosseiros na ZF, quanto maior a energia de soldagem. Ou seja, o aumento na energia de soldagem levou a um decréscimo na fração de ferrita $\alpha$. Além disso, as analises de EDS mostram que a concentração de austenita $(\mathrm{Y})$ na ZF é menor em relação à ZTA e MB, com maiores teores de $\mathrm{Cr}, \mathrm{N}$ e Mo e redução na concentração de Ni, Figura 2. Quanto a ZTA nota-se uma redução na concentração y quanto menor energia de soldagem, seguida de acréscimo na concentração e no tamanho de grãos de ferrita.

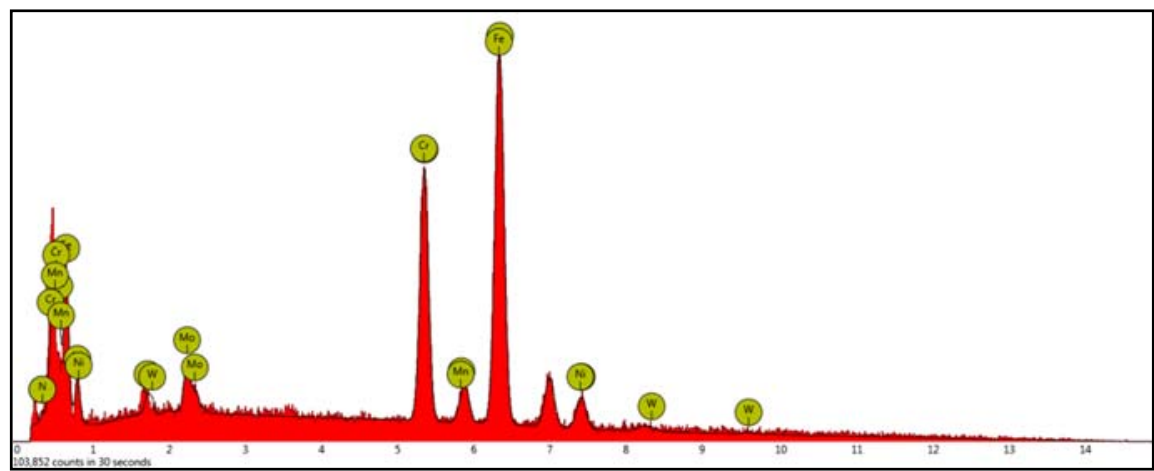

Figura 2 Analise por EDS na região de ZF considerando as três energias: a) J1 (EJ1 $=0,607 \mathrm{~kJ} / \mathrm{mm}) ; \mathrm{b}) \mathrm{J} 2\left(\mathrm{E}_{\mathrm{J} 2}=0,633 \mathrm{~kJ} / \mathrm{mm}\right)$ e c) $\mathrm{J} 3\left(\mathrm{E}_{\mathrm{J} 1}=0,427 \mathrm{~kJ} / \mathrm{mm}\right)$. 
A Figura 3 mostra as microestruturas características das juntas J1, J2 e J3 na ZF. Vê-se claramente a formação das fases $y$ e fase a com diferentes morfologias: austenita intergranular, austenita alotriomorfica (AA) nos contornos de grãos ferriticos (CGA) e austenita de Widmanstatten (AW) nos contornos de grão de ferrita crescendo ao longo dos planos da matriz em forma de plaquetas paralelas. Note que quanto maior a energia de soldagem e menor temperatura, menor a quantidade de austenita intergranular e maior a austenita de Widmanstatten, fator determinante no balanço microestrutural das fases $\alpha / \gamma$ [6]. As frações volumétricas dessas fases calculadas na ZF foram: Junta 1,38\% de ferrita a e $62 \%$ de austenita $\gamma$, com maior concentração de Widmanstatten se formando nos contornos de grãos de ferrita; Junta $2,37 \%$ de ferrita a e $63 \%$ de austenita y e Junta 3, $44 \%$ de ferrita a e $56 \%$ de austenita y que apresentou maior equilíbrio das fases, com erro percentual de $5 \%$. Nota-se uma diferença de $11 \%$ na fração de ferrita a a menor provavelmente devido a variação na energia de soldagem, o alto teor de $\mathrm{N}$ que estabiliza a fase $\mathrm{y}$ e a composição química dos elementos, com possíveis mudanças de resistência.
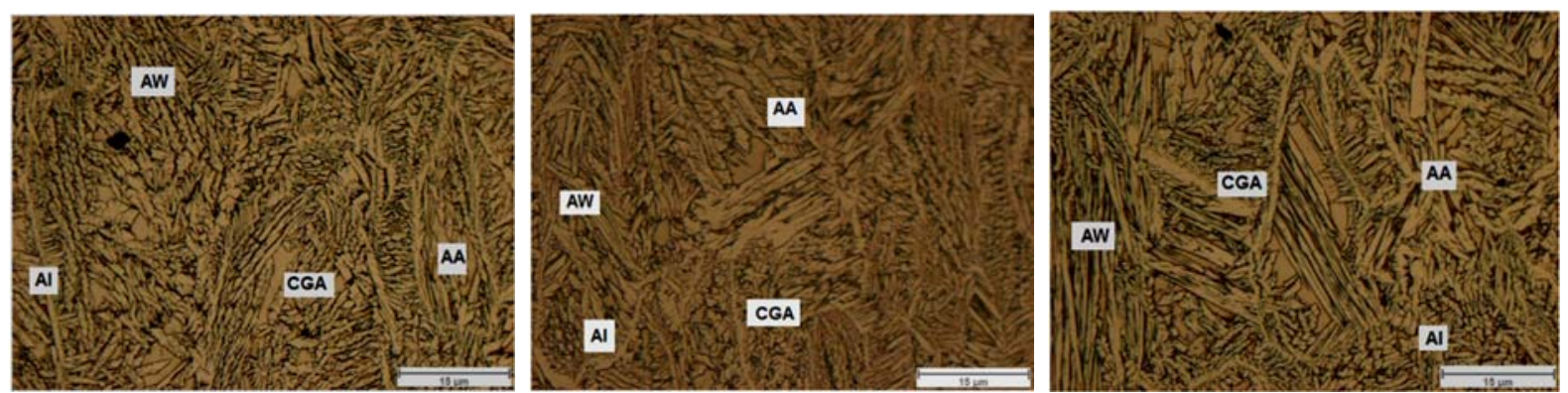

Figura 3 Microestrutura do aço SAF 2507 nas três juntas soldadas na região do último cordão de solda, ZF da Junta 1, Junta 2 e Junta 3.

Como pode ser visto na Figura 4, os padrões de difração de raios $X$ mostram a presença das fases $\alpha / \gamma$ com redução de intensidade da fase $\gamma$ e indicio de redução na taxa de transformação das fases $\alpha / \gamma$, quanto maior a energia de soldagem. Vê-se que as analises de raios $X$ evidenciam que as estruturas grosseiras formadas próximo à ZF é a fase $\alpha(z=2, B C C)$, identificada tanto na ZF quanto na ZTA em menor quantidade que a fase $y(z=4, F C C)$ em todas as juntas.

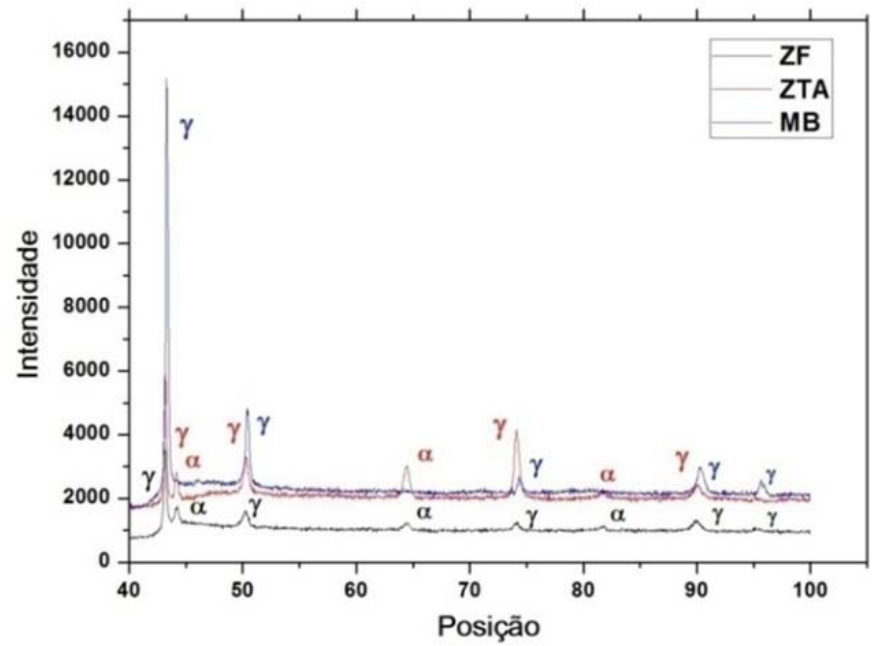

Figura 4 Padrão de difração de raios $X$ nas regiões de ZF-ZTA-MB das juntas soldadas do aço inoxidável superdúplex SAF 2507. 


\subsection{Ensaios de impacto}

Vê-se na Figura 5 que nos ensaios de impacto charpy do aço superduplex SAF 2507 realizados nas temperaturas de $-40^{\circ} \mathrm{C}$ e $25^{\circ} \mathrm{C}$ a energia absorvida na ZTA foi maior que na ZF e também no $\mathrm{MB}$ nas três juntas soldadas (J1, J2 e J3) com diferentes energias de soldagem, sendo um indicativo de boa tenacidade. Nota-se níveis de energia absorvida maior na ZTA que na ZF, quanto maior a energia de soldagem, devido provavelmente a formação de estruturas delgadas da fase $\alpha$, com a alta tenacidade resultante do pequeno tamanho de grão na ZTA e maior concentração de fase $\gamma$, que impede a propagação de trincas de clivagem originadas na fase a $[5,6]$. Vê-se também que quanto maior a temperatura de soldagem, maior a energia absorvida por impacto tanto na ZF quanto no MB. Os ensaios de impacto a $-40{ }^{\circ} \mathrm{C}$ mostrou redução na tenacidade, com mudança estrutural da fase a quando comparada com os dados à temperatura ambiente.
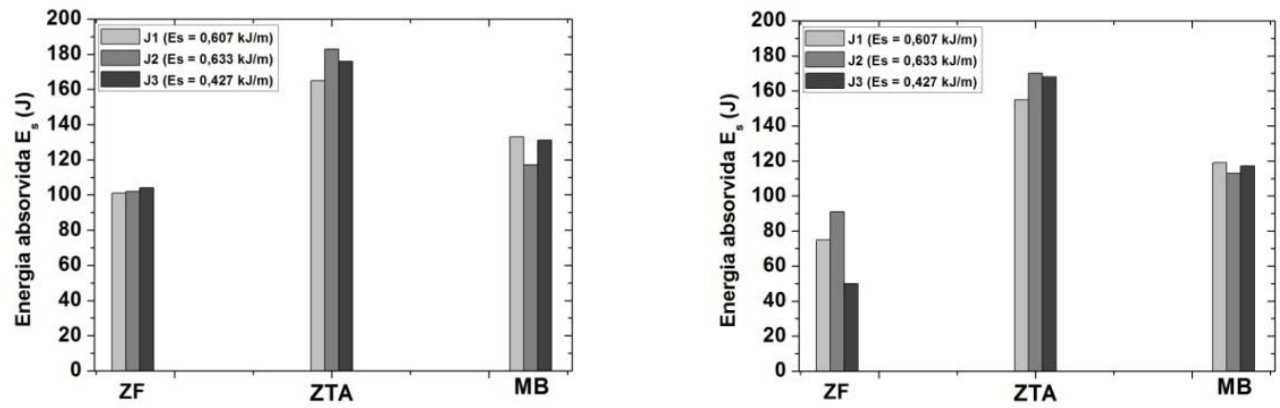

Figura 5 Energia média absorvida pelo material nos ensaios de impacto nas regiões de ZF-ZTA-MB nas condições de $25^{\circ} \mathrm{C}$ e $-40^{\circ} \mathrm{C}$.

Este comportamento está associado à quantidade elevada da fase y na ZTA, com redução significativa na tenacidade quando se avalia a ZF, aproximadamente pela metade. Entretanto, quando se avalia os resultados dos ensaios realizados a - 40 ${ }^{\circ} \mathrm{C}$, vê-se que a tenacidade diminui com redução da energia absorvida. Este comportamento dá-se devido à elevação na concentração da fase $\alpha$ e possivelmente a presença de precipitados de nitreto de cromo $\left(\mathrm{Cr}_{2} \mathrm{~N}\right)$, gerando uma microestrutura mais frágil com o coalescimento dos grãos ferriticos, criando tensões residuais e aumento da fase $\gamma$. [6]. Vê-se que há aumento no tamanho de grão das fases e redução do número de grãos quando a tenacidade ao impacto é reduzida.

\subsection{Ensaios de corrosão por pite}

Os ensaios de corrosão por pite, sob a norma ASTM G48 - prática A com imersão em solução ácida por $24 \mathrm{~h}$ a $22^{\circ} \mathrm{C}$, apresentou uma perda de massa por área de $0,0308 \mathrm{~g} / \mathrm{cm}^{2}$ na amostra da junta $\mathrm{J} 1$ e de $0,0353 \mathrm{~g} / \mathrm{cm}^{2}$ na junta J2. Nota-se que a perda de massa foi maior que $0,0001 \mathrm{~g} / \mathrm{cm}^{2}$, evidenciando a formação de pites na interface $\alpha / \gamma$ consumindo o interior dos grãos ferriticos, como mostra a Figura $6 . \mathrm{Na}$ junta J3 a perda de massa foi menor $0,0264 \mathrm{~g} / \mathrm{cm}^{2}$ com menor energia de soldagem. 

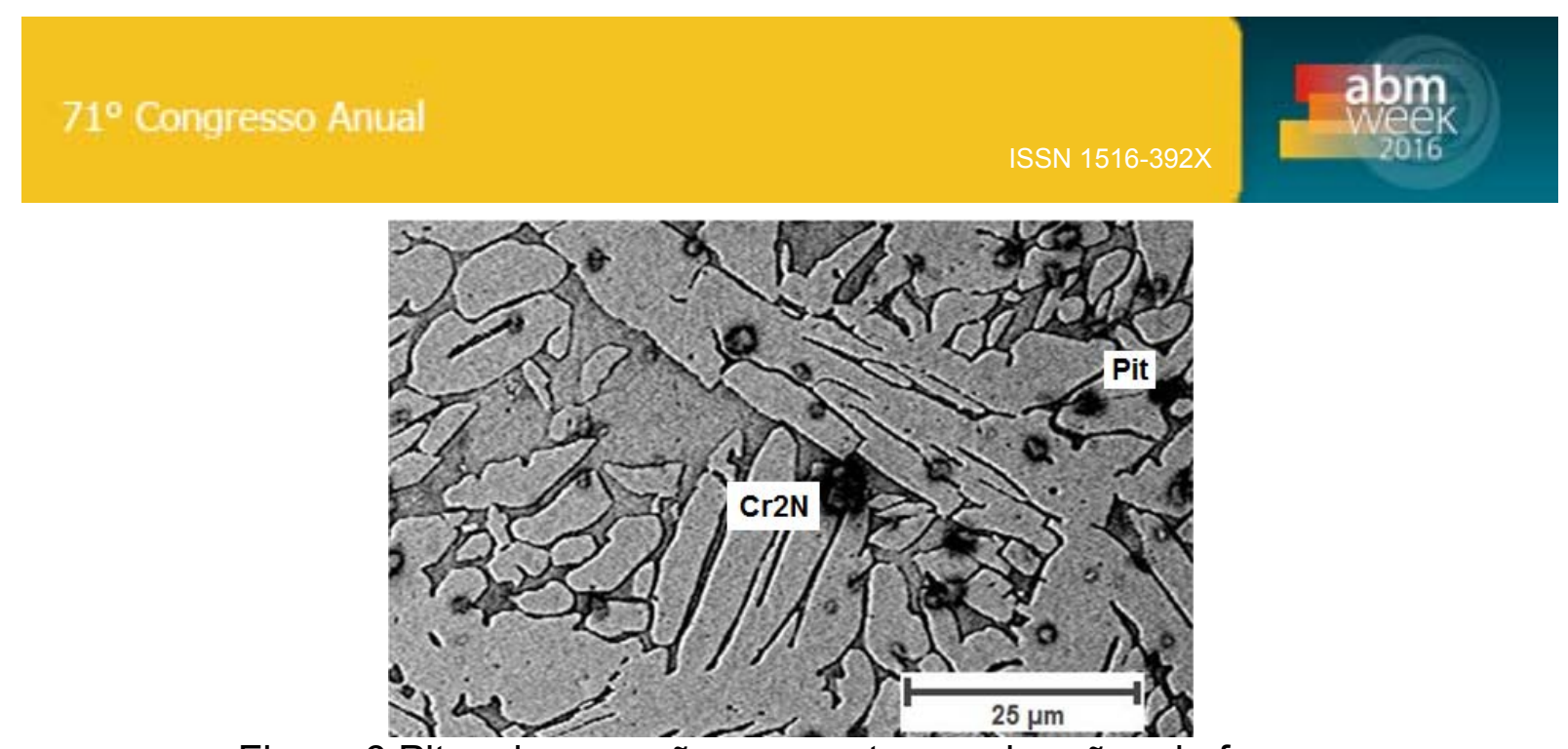

Figura 6 Pites de corrosão nos contornos de grãos da fase $\alpha$.

As analises de microscopia evidenciaram a presença de impurezas. As analises por EDS realizada no interior dos pites apresentaram altos teores de $\mathrm{Mn}$ e $\mathrm{Si}$, indicando que a nucleação e propagação dos pites ocorreu em regiões de inclusões com precipitados de sulfeto de manganês (MnS), que favorecem a formação do pite de corrosão nos sítios preferenciais, como nas bandas de deformação, na interface $\alpha / \gamma$, gerando descontinuidade no filme passivo, Figura 6. Esta é uma das razões de fraturas nos aços quando sujeita a condições de deformação, acompanhada de mudanças microestruturais e tensões residuais acumuladas. Note que a fase $y$ apresentou menos ataque localizado (pites) quanto à fase $\alpha$, provavelmente atribuída ao maior conteúdo de Ni na fase $\mathrm{\gamma}$, com maior resistência a corrosão.

A Figura 7 apresenta os valores estimados do PREN para as três diferentes energias de soldagem aplicada no trabalho, a partir de equações empíricas na literatura [4]. Vê-se que a coexistência das fases $\alpha / \gamma$ modifica os valores estimados do PREN, com desempenho determinado pela fase com menor valor. Os valores de PREN das fases devido à partição dos elementos de liga calculados foram: $\operatorname{PREN}_{(\mathrm{MB})}=41,66 ; \operatorname{PREN}_{(\mathrm{ZF})}=41,31 ; \operatorname{PREN}_{(\alpha)}=37,79 ; \operatorname{PREN}_{(\mathrm{y})}=45,59$. Nota-se um valor elevado na fase $\mathrm{y}$ na condição de maior energia de soldagem, provavelmente devido à presença de elementos de liga, como o $\mathrm{N}$ e o $\mathrm{Ni}$ que aumentam a tenacidade, elevam a resistência ao pite e aumentam a taxa de encruamento, estabilizando a fase $\gamma$, como reportado por J.W. Simmons [6].

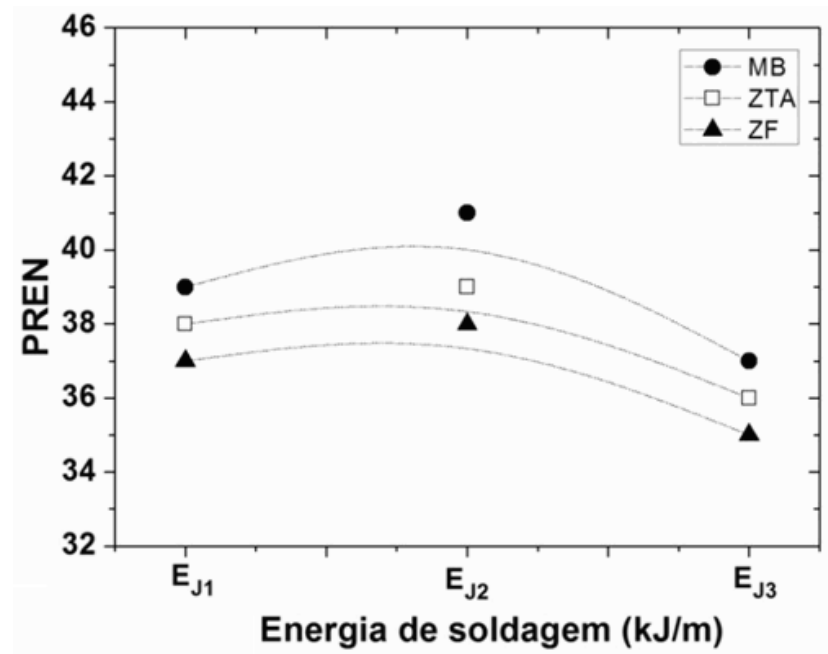

Figura 7 Correlação dos valores de PREN das fases $\alpha / y$ do aço SAF 2507 quanto às energias de soldagem aplicadas. 
Vale citar que o $\mathrm{N}$ não previne a formação da fase $\sigma$, mas atrasa sua formação, onde sua principal função é o balanço e aumento da taxa de transformação das fases $\alpha / y$ [5]. Então quanto maior o PREN, maior é a tenacidade e resistência à corrosão por pites. Observe também que com aumento da temperatura o PREN $\operatorname{Pa}_{(\alpha)}$ diminuiu, enquanto o PREN $(\mathrm{y})$ aumentou. Quanto menor a energia de soldagem, menor a diferença das fases $\alpha / \gamma$, indicando maior fração da fase $\alpha$, reduzindo o PREN. Este comportamento está em acordo os valores calculados para o $\mathrm{Cr}_{(\mathrm{eq})}=$ 29,5 e $\mathrm{Ni}_{(\text {eq })}=15,4$, que definem as regiões de ZTA e ZF como as mais propicias a formação de pites de corrosão (regiões com menores teores de $\mathrm{Cr}$ e Mo), segundo as condições de soldagem.

\subsection{Ensaios de microdureza}

Os resultados de microdureza calculados nas três juntas, mostrou variações na região trifásica ZF-ZTA-MB, Figura 8. Nota-se que o maior pico de microdureza ocorreu na ZF em média com $314 \mathrm{Hv}$, enquanto o valor mais baixo ocorreu no MB com $179 \mathrm{Hv}$. A microdureza da ZTA ficou neste intervalo com $248 \mathrm{Hv}$, evidenciando uma repartição térmica na junta soldada. Note que a soldagem promoveu aumento de microdureza na ZTA, quanto maior o aporte térmico e as regiões de maior microdureza que são também as de maior fração de fase $\mathrm{Y}$ atribuído aos maiores teores de $\mathrm{N}$ e Ni, como visto na Fig. 2.

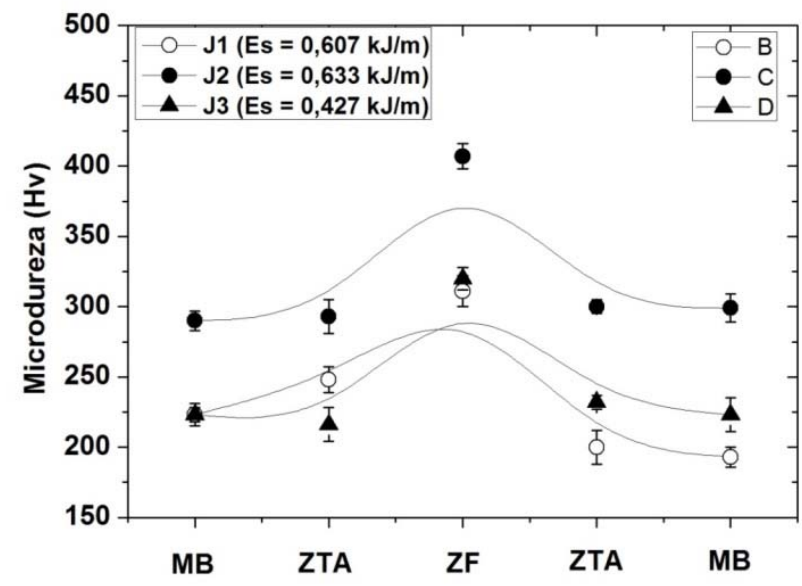

Figura 8 Perfil da microdureza das juntas soldadas nas regiões de ZF-ZTA-MB: Junta 1STT, Junta 2STT e Junta 3STT convencional.

A medida do gradiente de microdureza da Junta 2 apresentou-se elevado quando comparado com a Junta 1: MB (290 Hv); ZTA (293 Hv) na ZF (407 Hv), onde o maior valor na ZF reflete também a menor tenacidade dessa região em comparação a ZTA e MB. Por fim, a Junta 3 apresentou um valor em média igual no MB aos das outras juntas $(223 \mathrm{Hv})$, mas apresentou microdureza na ZTA mais baixa, em torno de 216 $\mathrm{Hv}$, assim como na ZF com microdureza de $311 \mathrm{Hv}$. Note que quanto maior a energia de soldagem maior o nível de microdureza, mas há uma redução de microdureza quando se avalia o sentido ZF-ZTA-MB, ou seja, afasta-se do centro de solda com mesmo valor de energia de soldagem.

Note que nas regiões de ZF e ZTA a microdureza apresentou valores maiores que no $\mathrm{MB}$, sendo a microdureza na ZTA variável com tendência a redução à medida que se aproxima do $\mathrm{MB}$, com diminuição na tenacidade e na resistência a corrosão 
por pite, provavelmente devido ao crescimento de grãos e a presença de ferrita sob coalescimento, reduzindo o efeito de endurecimento [25]. A diferença de microdureza na ZTA é atribuída às diferentes morfologias das fases $\alpha / \gamma$ e na distribuição da fase $\sigma$. Os ensaios de microdureza evidenciam que a resistência mecânica das regiões da ZF é maior que a do MB, este comportamento deve-se a presença de $\mathrm{N}$ em solução sólida, refino de grão austenitico e endurecimento por efeito dos precipitados da fase $\sigma$, com austenita retida $(\gamma s)$ nos contornos de grãos de ferrita que limita a recristalização e favorece a ocorrência de tamanho de grão fino, contribuindo para o aumento da resistência da região soldada.

\subsection{Aspecto microestrutural}

A Figura 9 mostram as analises por microscopia eletrônica de varredura (MEV), onde se observou mudanças de composição por EDS na fração das fases $\alpha / \gamma$ no processo de soldagem, com a presença de fase $\sigma$ nos contornos de grãos ferriticos formados a partir da ferrita a com maior difusão de $\mathrm{Cr}$ e identificação de colônias de precipitados de nitreto de cromo $\left(\mathrm{Cr}_{2} \mathrm{~N}\right)$ nos contornos da fase $\alpha$, na interface $\alpha / \alpha$ e em pontos triplos, como produto do ciclo térmico imposto durante o processo de soldagem, comprometendo a tenacidade, microdureza e a resistência à corrosão por pite com menor PREN. Note que estes resultados estão de acordo com o calculo do diagrama de fase em equilíbrio por Facstage que também evidenciou a formação das fases: Fase $\alpha$, Fase $\gamma$, Fase $\sigma, \mathrm{Cr}_{2} \mathrm{~N}$ e $\mathrm{M}_{23} \mathrm{C}_{6}$, como mostra a Fig. 10.
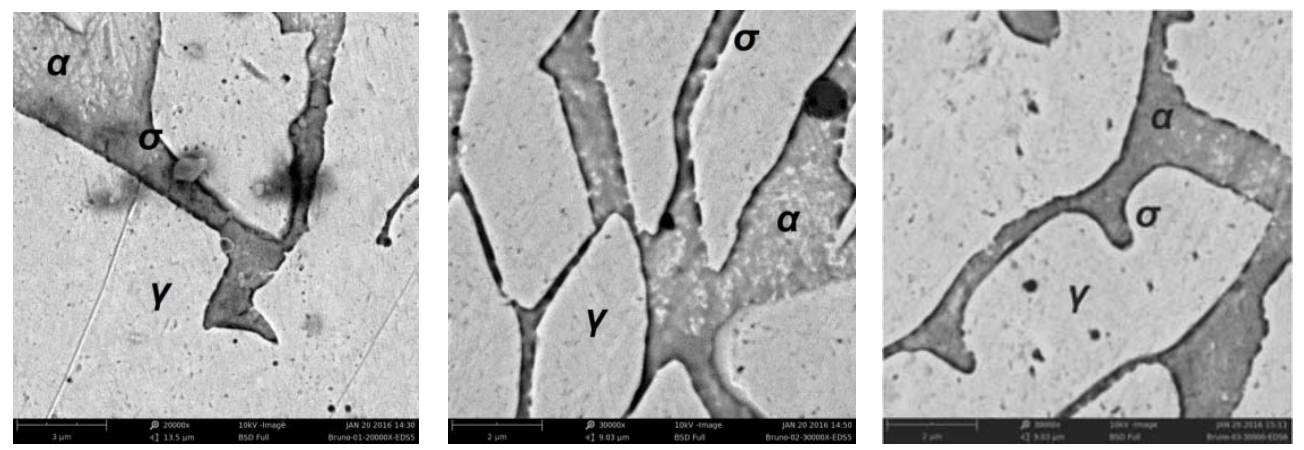

Figuras 9 Formação da fase $\sigma$ e $\mathrm{Cr}_{2} \mathrm{~N}$ nos contornos de grãos das fases $\alpha / \gamma$ na ZTA com progressão para a fase a via microscopia eletrônica de varredura.

Vê-se que na ZF a quantidade da fase $y$ é maior que na ZTA e no MB com a presença da fase $\sigma$ precipitada nos contornos de grãos ferriticos em pequenas frações que podem gerar trincamento por corrosão pontual. Por isso deve-se evitar a formação de fase $\sigma$ durante o resfriamento de solidificação, pois reduzem de forma acentuada a tenacidade do material, porque a fase $\sigma$ remove e consome $\mathrm{Cr}$, Mo e $\mathrm{N}$ levando as regiões adjacentes a empobrecimento e redução no PREN, principalmente na região de ZF com menor energia de soldagem [6]. Assim, esperase que os resultados obtidos permitem estabelecer diretrizes para a realização de procedimentos de reparo nos aços inoxidáveis superdúplex SAF 2507 utilizando processos de soldagem. 


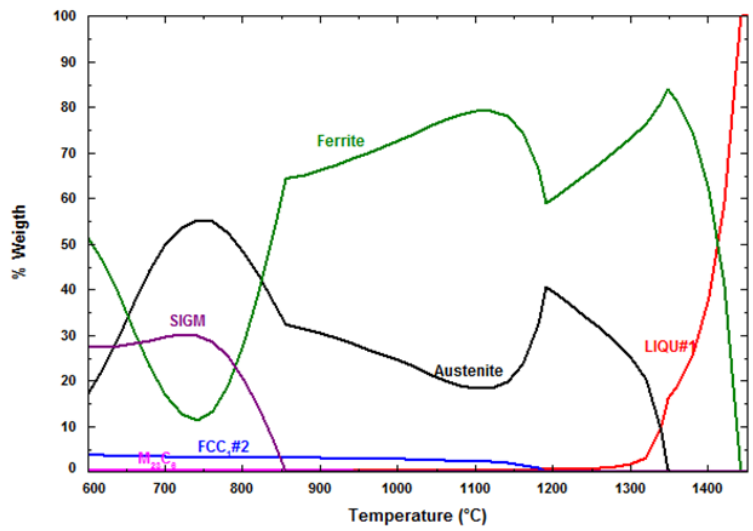

Figura 10 Cálculo termodinâmico do diagrama de equilíbrio por Facstage das amostras CR do aço inoxidável duplex SAF 2507 em função da temperatura.

\section{CONCLUSÃO}

- As microestruturas evidenciaram a presença das fases $\alpha / \gamma$ sob a forma intergranular, Widmanstatten e alotriomorficas, com formação pontual da fase $\sigma$ nos contornos de grãos, preferencialmente nas interfaces $\alpha / \gamma$ e crescimento dos grãos da fase ferrita $\alpha$, com forte influência da energia de soldagem, resultando em mudanças de microdureza (maior na ZTA e no MB) e tenacidade nas três regiões ZF-ZTA-MB, com acréscimo na quantidade da fase $y$ na ZF e diminuição de fase $\alpha$ com o aumento da energia de soldagem.

- A ZTA e o MB apresentaram boa tenacidade a temperatura ambiente e também sob baixa temperatura $\mathrm{a}-40^{\circ} \mathrm{C}$ com diferentes energias de soldagem. Entretanto a tenacidade na ZF diminuiu significativamente, mesmo com a maior formação da fase $\gamma$, devido ao coalescimento dos grãos ferriticos e formação da fase $\sigma$.

- As analises de corrosão apresentaram maior perda de massa quanto maior a energia de soldagem, com formação dos pites na interface $\alpha / \gamma$ evoluindo para a fase $\alpha$, onde a mudança no PREN devido a partição dos elementos modificou a coexistência das fases, com $\operatorname{PREN}_{(\mathrm{y})}$ maior que o $\operatorname{PREN}_{(\alpha)}$ quanto maior a energia.

\section{REFERÊNCIAS}

1 Badji R, Bouabdallah M, Bacroix B, Kahloun C, Belkessa B, Maza H. Phase transformation and mechanical behavior in annealed 2205 duplex stainless steel welds. Mater Charact 2008;59: 447-53.

2 Brandi, S.D. Some aspects of weldability and jointability of duplex stainless steels. Materials Science Forum. 2003 (3): 4063-4068.

3 Sato YS, Nelson TW, Sterling CJ, Steel RJ, Pettersson C-O. Microstructure and mechanical properties of friction stir welded SAF 2507 super duplex stainless steel. Mater Sci Eng A. (2005):376-84.

4 Solomon, HD., Koch, E.F. High temperature precipitation of $\alpha^{\prime}$ in a multicomponent duplex stainless steel. Scripta Metallurgica. 1979 (10): 971-974.

5 Rahmani M, Eghlimi A, Shamanian M. Evaluation of microstructure and mechanical properties in dissimilar austenitic/super duplex stainless steel joint. J Mater Eng Perform 2014;23: 3745-53.

$6 \quad$ H.-Y. Ha et al. Min-Ho Jang a,b, Tae-Ho Lee a, Joonoh Moon a / Materials Characterization 106 (2015) 338-345. 